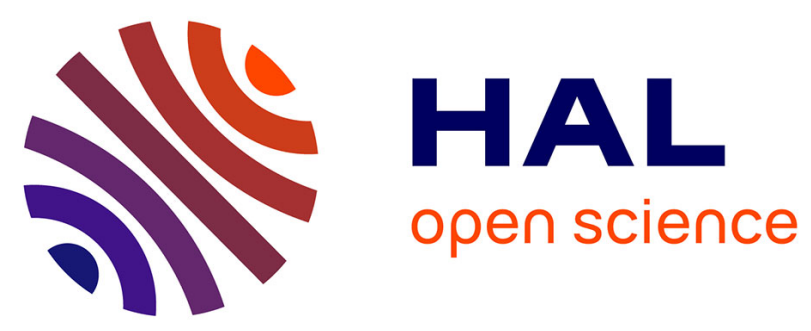

\title{
Mucositis does not lead to false-positivity of the Platelia enzyme-linked immunosorbent assay
}

\author{
Z. Racil, I. Kocmanova, B. Weinbergerova, M. Toskova, J. Winterova, M. \\ Lengerova, L. Buresova, S. Timilsina, J. Mayer
}

\section{To cite this version:}

Z. Racil, I. Kocmanova, B. Weinbergerova, M. Toskova, J. Winterova, et al.. Mucositis does not lead to false-positivity of the Platelia enzyme-linked immunosorbent assay. European Journal of Clinical Microbiology and Infectious Diseases, 2010, 29 (7), pp.851-855. 10.1007/s10096-010-0938-7 . hal00589678

\section{HAL Id: hal-00589678 \\ https://hal.science/hal-00589678}

Submitted on 30 Apr 2011

HAL is a multi-disciplinary open access archive for the deposit and dissemination of scientific research documents, whether they are published or not. The documents may come from teaching and research institutions in France or abroad, or from public or private research centers.
L'archive ouverte pluridisciplinaire HAL, est destinée au dépôt et à la diffusion de documents scientifiques de niveau recherche, publiés ou non, émanant des établissements d'enseignement et de recherche français ou étrangers, des laboratoires publics ou privés. 


\title{
Mucositis does not lead to false-positivity of the Platelia Aspergillus enzyme-linked immunosorbent assay
}

\author{
Z. Racil $\cdot$ I. Kocmanova $\cdot$ B. Weinbergerova $\cdot$ \\ M. Toskova $\cdot$ J. Winterova $\cdot$ M. Lengerova . \\ L. Buresova $\cdot$ S. Timilsina $\cdot$ J. Mayer
}

Received: 10 November 2009 / Accepted: 3 April 2010/Published online: 30 April 2010

(C) Springer-Verlag 2010

\begin{abstract}
We are reporting a study evaluating the crossover of antigens reacting in Platelia Aspergillus (PA) enzyme-linked immunosorbent assay (ELISA) from faeces to vessels during mucositis as a possible cause of false-positivity of this test. In our series of 102 episodes of different grades of mucositis, we found strong reactivity of faeces in the PA ELISA test irrespective of the grade of mucositis, the percentage of oral food intake or the presence of total parenteral nutrition. However, none of the patients included in the study were positive in the serum (when the criterion of two samples with cut-off index of positivity [IP] $>0.5$ was used).
\end{abstract}

\section{Introduction}

The detection of the circulating galactomannan (GM) antigen is of high importance in the early diagnosis of invasive

Z. Racil $(\bowtie) \cdot$ B. Weinbergerova $\cdot$ M. Toskova $\cdot J$. Winterova

$\mathrm{M}$. Lengerova $\cdot \mathrm{J}$. Mayer

Department of Internal Medicine Hemato-Oncology,

Masaryk University and University Hospital Brno,

Jihlavska 20,

62500 Brno, Czech Republic

e-mail: zracil@fnbrno.cz

I. Kocmanova

Department of Microbiology, University Hospital Brno,

Brno, Czech Republic

L. Buresova

Institute of Biostatistics and Analyses,

Faculty of Medicine and the Faculty of Science,

Masaryk University,

Brno, Czech Republic

S. Timilsina

Medical Faculty, Masaryk University,

Brno, Czech Republic aspergillosis (IA) in patients with a haematological malignancy. Its regular monitoring in the serum using Platelia Aspergillus (PA) enzyme-linked immunosorbent assay (ELISA) test (BioRad, France) is standard in most haematooncological units. A meta-analysis noted the test's sensitivity of $79 \%$, specificity $86 \%$ and overall accuracy of $89 \%$ [1]. However, false-positive results are one of the major limits of this assay. During recent years, two major factors contributing to this false-positivity of GM ELISA test were well defined-the administration of some antimicrobials (piperacillin/tazobactam, amoxicillin and ampicillin) and Plasma-Lyte solution (Baxter). These represent $>90 \%$ of GM false-positive results in some centres $[2,3]$. Mucositis and the passage of dietary GM or exoantigens from bacteria or fungi into the blood circulation via mucosal lesions of the gastrointestinal tract has been hypothesised by some investigators to be another source of false-positivity of the test $[4,5]$. However, till now, there have not been any studies evaluating this theory. We, therefore, conducted a study to evaluate the clinical relevance of mucositis and its severity, as well as the amount of oral intake during the period of mucositis, to GM ELISA test performance in patients with a haematological malignancy.

\section{Patients and methods}

Between December 2007 and August 2009, 75 patients treated with chemotherapy with the risk of mucositis occurrence were enrolled in our study. All patients signed their written informed consent for inclusion in the study. Any time during the episode of a certain degree of mucositis, two consecutive blood samples and one stool sample for GM detection were obtained within a 24-h interval in patients with different grades of mucositis. A patient could be included in the study several times if the grade of mucositis 
progressed. The severity of oral mucositis was scored according to the World Health Organization (WHO) scale [6] and for the grading of intestinal mucositis the National Cancer Institute Common Toxicity Criteria (NCI-CTC) Version 3.0 scale for non-infectious diarrhoea was used [7].

At the time of sampling, none of the included patients had signs of IA (according to the European Organization for Research and the Treatment of Cancer/Mycosis Study Group) [8] or any other invasive fungal disease and had prophylaxis or empirical treatment with a mould-active drug. All patients received oral or intravenous co-trimoxazole as Pneumocystis jiroveci prophylaxis and $97 \%$ of patients had anti-fungal prophylaxis with fluconazole at the time of sampling. Antibiotics used for the empirical treatment of febrile neutropaenia (if present) consisted of: piperacillin/ tazobactam (only GM-negative batches were used for treating our patients), cefepime, amikacin and meropenem. The percentage of standard oral food intake (regularly monitored by nursing staff) and the presence of total parenteral nutrition at the time of sampling were collected.

PA ELISA kit was used for GM detection. Analysis of serum samples was performed according to the manufacturer's recommendation. For the analysis of stool samples, $1 \mathrm{~g}$ of faeces was disintegrated in $1 \mathrm{ml}$ of distilled water and then centrifuged at $3,000 \mathrm{rpm}$ for $10 \mathrm{~min}$. If there was diarrhoea, $2 \mathrm{ml}$ of faecal material were directly centrifuged. After centrifugation, $300 \mu \mathrm{l}$ of supernatant was tested in the PA ELISA test. Reactivity of the assay was expressed as an index of positivity (IP) per stool sample. Faecal specimens were tested within $48 \mathrm{~h}$ after collection and were stored at $2-8^{\circ} \mathrm{C}$ until the time of analysis.

\section{Results}

Two hundred and four blood and 102 stool samples obtained in 102 episodes of mucositis in 75 patients (1.4 episode per patient) with different haematological malignancies were analysed for GM presence (blood samples) and PA ELISA reactivity (stool samples), respectively. Baseline haematological disease, as well as anti-cancer treatment are shown in Table 1.

Stool samples were highly reactive in the PA ELISA assay, with a median IP of 3.52 (range 0.07-14.4). The reactivity of faeces in the PA ELISA assay was not significantly influenced by the mucositis grade, percentage of standard daily oral intake or the presence of total parenteral nutrition (Table 2, Fig. 1). The difference between the median reactivity of faecal samples obtained during different grades of mucositis in the PA ELISA assay was not statistically significant $(p=0.416$; Kruskal-Wallis analysis of variance [ANOVA]). The medians of IPs of stool samples obtained during episodes with various percen-
Table 1 Demographic data

\begin{tabular}{ll}
\hline & No. (\%) [range] \\
\hline No. of patients & 75 \\
Male/female & $39(52 \%) / 36(48 \%)$ \\
Median age (years) & $56[20-71]$ \\
Baseline disease & \\
Acute myeloid leukemia/myelodysplastic & $11(15 \%)$ \\
$\quad$ syndrome & $14(19 \%)$ \\
Acute lymphoblastic leukemia & $22(29 \%)$ \\
Multiple myeloma & $19(25 \%)$ \\
Non-Hodgkin's lymphoma & $5(7 \%)$ \\
Hodgkin's lymphoma & $4(5 \%)$ \\
Other & \\
Type of anti-cancer treatment & $11(15 \%)$ \\
Allogeneic HSCT & $6(7 \%) / 5(8 \%)$ \\
$\quad$ Related/unrelated & $8(11 \%) / 3(4 \%)$ \\
$\quad$ Myeloablative/non-myeloablative & $38(51 \%)$ \\
$\quad$ conditioning & $5(7 \%)$ \\
Autologous HSCT & $8(10 \%)$ \\
acute leukemia/myelodysplastic syndrome & $10(13 \%)$ \\
Consolidation chemotherapy of acute leukemia & $8(4 \%)$ \\
Convention chemotherapy of lymphoma & 102 \\
Other & $21(21 \%)$ \\
No. of monitored episodes of mucositis & $42(41 \%)$ \\
Oral mucositis & $39(38 \%)$ \\
Ontestinal mucositis & \\
\hline
\end{tabular}

HSCT $=$ haematopoietic stem cell transplantation

tages of standard daily food intake were not different: $100 \%$ to $75 \%$ of daily amount, median IP $3.52 ; 74 \%$ to $50 \%, 4.53$; $49 \%$ to $25 \%, 4.47 ; 24 \%$ to $0 \%, 3.02$ ( $p=0.666$; KruskalWallis ANOVA). Finally, the median IP in faeces from episodes with total parenteral nutrition were slightly lower compared to other samples, but this was not statistically significant ( 2.15 vs. 3.98; $p=0.090$; Mann-Whitney).

In contrast, GM levels in serum samples were independent of GM in faeces and grade of mucositis (Table 1). The median GM IP in serum samples was 0.11 (range 0.04-2.48). When criterion for the test positivity of one sample with IP $>0.5$ was used, only one patient (moreover, without mucositis) would be marked as GM-positive. However, a consecutive sample from the same patient had GM IP $<0.5$ and using common clinical criterion for PA ELISA test positivity (two samples with IP $>0.5$ ), the patient was identified as GM-negative.

\section{Discussion}

In the presented study, we have found no false-positive results of the PA ELISA test (defined as GM IP $>0.5$ in two 
Table 2 Median and 25-75\% interquartile range of Platelia Aspergillus (PA) enzyme-linked immunosorbent assay (ELISA) assay index of positivity (IP) in the serum and stool samples, percentage of daily oral intake and percentage of patients with total parenteral nutrition during different grades of mucositis according to the World Health Organization (WHO) and National Cancer Institute Common Toxicity Criteria (NCI-CTC) scales

\begin{tabular}{|c|c|c|c|c|c|}
\hline $\begin{array}{l}\text { Grade of } \\
\text { mucositis (no. } \\
\text { of tested episodes) }\end{array}$ & $\begin{array}{l}\text { Median IP ( } 25-75 \% \\
\text { interquartile range): } \\
\text { serum samples }\end{array}$ & $\begin{array}{l}\text { No. of episodes with single/ } \\
\text { consecutive IP }>0.5 \text { in serum } \\
\text { samples (positive result) }\end{array}$ & $\begin{array}{l}\text { Median IP }(25-75 \% \\
\text { interquartile range): } \\
\text { stool samples }\end{array}$ & $\begin{array}{l}\text { Median \% of } \\
\text { standard daily } \\
\text { oral intake }\end{array}$ & $\begin{array}{l}\% \text { of patients with } \\
\text { total parenteral } \\
\text { nutrition }\end{array}$ \\
\hline $0(n=22)$ & $0.13(0.09-0.16)$ & $1 / 0$ & $2.80(1.62-8.19)$ & 100 & $0 \%$ \\
\hline $1(n=19)$ & $0.13(0.09-0.16)$ & $0 / 0$ & $3.59(0.64-8.12)$ & 90 & $0 \%$ \\
\hline $2(n=22)$ & $0.12(0.08-0.18)$ & $0 / 0$ & $4.61(2.83-9.51)$ & 50 & $0 \%$ \\
\hline $3(n=19)$ & $0.09(0.08-0.15)$ & $0 / 0$ & $5.69(0.28-10.5)$ & 10 & $16 \%$ \\
\hline $4(n=20)$ & $0.10(0.07-0.16)$ & $0 / 0$ & $2.42(1.04-6.24)$ & 0 & $100 \%$ \\
\hline
\end{tabular}

$\mathrm{IP}=$ index of positivity

consecutive serum samples) in 75 patients with haematological malignancies during 102 episodes of different grades of mucositis. However, 102 matched stool samples obtained in the same period revealed strong reactivity of faeces in this assay with a median IP of 3.5. This intensive reactivity of faeces was not influenced by the grade of mucositis, daily oral food intake amount or nourishment with total parenteral nutrition. Thus, our study did not confirm the possibility of crossover of these faecal antigens during a period of mucositis to the serum and their influence on the outcome of the assay reaction when testing these serum samples.

The specificity of the PA ELISA test for the early diagnosis of IA is hampered by the occurrence of falsepositive results. Although a majority of these events could be explained by the administration of penicillin antimicrobials or gluconate containing electrolyte solutions, till now, almost every review of the literature concerning GM detection also reports mucositis and passage of the antigen through damaged mucosa as a possible source of the false-positivity of the assay.

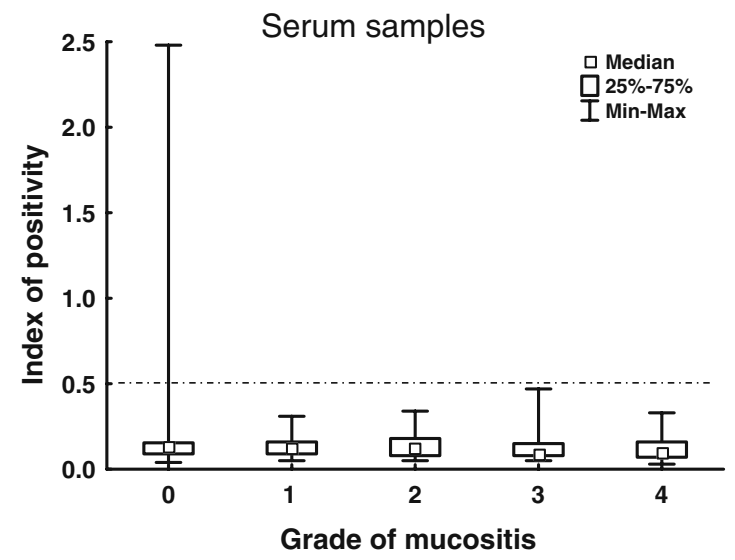

Fig. 1 Median, 25-75\% interquartile range, minimal and maximal index of positivity (IP) of Platelia Aspergillus (PA) enzyme-linked immunosorbent assay (ELISA) in the serum and stool samples during
However, there have been only very limited data published so far concerning and supporting this hypothesis. Ansorg et al. studied the presence of GM antigen using a latex agglutination (LA) test in foods and faeces and found $79 \%$ of hospital meals and all faeces samples from haematopoietic stem cell transplantation (HSCT) recipients and healthy volunteers to be reactive in this GM LA assay [4]. The authors assume that, during the period of mucosal damage, these faecal antigens obtained from food could cross through mucosal lesions and, henceforth, cause test positivity. Mennink-Kersten et al. hypothesised that the false-positivity of the PA ELISA assay in premature neonates with immature intestinal mucosa might be due to the presence of a lipoteichoic acid of Bifidobacterium spp. colonising the neonatal gut [9]. Tested neonatal faeces strongly reacted with the PA ELISA assay [10]. Since bifidobacteria or their components could pass across the damaged mucosa, they can hypothetically also be the cause of false-positive reactivity in immunocompromised patients with mucositis [10]. However, clinical studies confirming

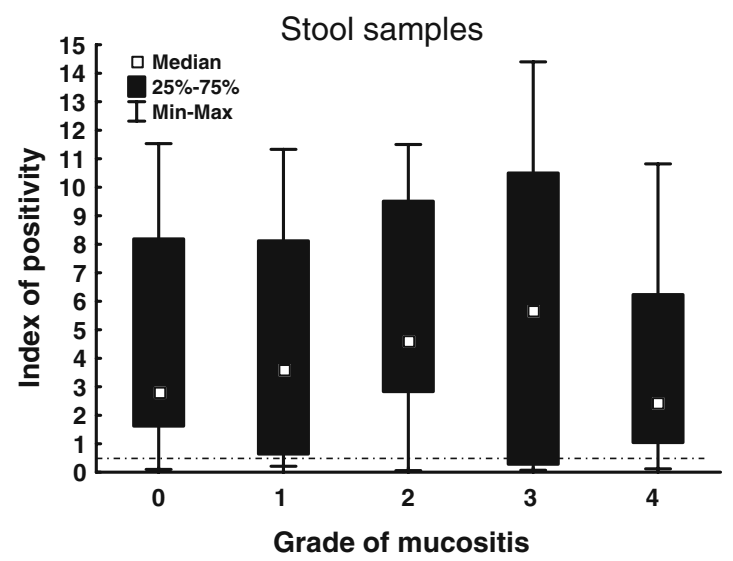

different grades of mucositis according to the World Health Organization (WHO) and National Cancer Institute Common Toxicity Criteria (NCI-CTC) scales 
the hypothesis and laboratory findings of these two authors have not been performed till now.

Herbrecht et al. found a lower positive predictive value (PPV) of the PA ELISA test caused by a high frequency of false-positive results in the group of adult patients after allogeneic HSCT (42.9\%). According to their previous findings with high amounts of GM in the foods supplied to children with positive tests, the same hypothesised mechanism could be the explanation for the false-positivity of the assay during the first month after allogeneic HSCT when mucosal damage is frequent [5]. However, other investigators have failed to prove this theory [11].

Finally, Blijlevens et al. found no false-positivity of the PA ELISA assay in their study of patients after HSCT during the period of severe mucositis if they were fed exclusively by total parenteral nutrition. However, they disclosed that, if the damaged digestive tract is exposed to food containing GM, the translocation of the antigen can potentially occur, but no study has been done on this field [12].

To our knowledge, this is the first study analysing faeces (as a major part of gut compartment) and blood for PA ELISA reactivity in explicitly defined stages of mucositis in haematooncological patients. In accordance with Ansorg et al., a vast majority of stool samples from our patient group were found to be strongly reactive in the PA ELISA test. The reason for this positivity could be antigens of food origin, as Ansorg et al. described. However, because the stool samples were also strongly reactive in patients with total parenteral nutrition, there must be other sources of GM or antigens reacting with the assay (e.g. bifidobacteria, but this was not analysed in our study). Blijlevens et al. mentioned the necessity of taking food consumption into account when monitoring GM in patients (especially with mucositis), because this could be a source of GM for possible mucosal translocation. However, our data showed that, if their hypothesis would be correct, GM (or other antigens reacting with the test) will cross damaged mucosal barriers also in their group of patients with total parenteral nutrition, because faeces are strongly reactive in the PA ELISA assay, irrespective of food intake.

In all accounts, our study showed that there is no crossover of GM or other antigens reacting with the PA ELISA assay from strongly reactive stool to the serum through differently damaged mucosa and the previous hypothesis of other authors $[4,10,12]$ were not confirmed. If this antigen cross would have happened, it would have been very occasional, because in 58 serum samples obtained in 29 episodes of severe mucositis (grade 3 and 4) in our study, none had GM IP $>0.5$. The only positive serum sample in our study was acquired from a patient without mucositis and this positivity was probably caused by GM contamination of the sample, because a paired serum sample from the same day was negative in the assay (IP 0.17).

Finally, a high frequency of false-positive results of the PA ELISA assay and low PPV in Herbrecht et al.'s study is impossible to explain by the presence of mucositis. It must be known that this mentioned study was performed several years before the information about the most important reasons for false-positivity of the PA ELISA test (antibiotics and Plasma-Lyte solution) was identified. It is very likely that these factors, but not mucositis, are of a higher probability to have caused the mentioned results.

Our results could have several limitations. Firstly, patients could be included several times in the study, when their grade of mucositis changed. However, only 27 episodes occurred in patients already included in the study, and in half of them, the first sample had been obtained during the period of mucositis grade 0 or 1 . Thus, this could not have influenced results from the most important group of samples obtained during severe mucositis, when the possibility of crossover of antigens from the intestinal tract to the serum would be expected. Secondly, the PA ELISA test is not validated for faecal samples and, thus, the results from stool samples must be considered as indicative. However, the main goal of our study was to show a strong reactivity of faecal samples in the PA ELISA test that is not influenced by oral food intake. Thirdly, in our study, we have not analysed the source of PA ELISA test reactivity of faeces. However, we build on the knowledge of the conclusions of Mennink-Kersten et al.'s and Ansorg et al.'s studies, which describe several reasons for this reactivity, and we have concentrated on the confirmation or exclusion of crossover of these antigens via damaged mucosa.

In summary, our study showed high reactivity of faeces (irrespective of the amount of oral food intake) in the PA ELISA assay and, for the first time, it has been confirmed that there is no or very limited crossover of GM or other antigens causing reactivity of the PA ELISA test (e.g. lipoteichoic acid of Bifidobacterium spp.) via the damaged mucosa in adult patients with haematological malignity. Thus, the presence of antigens reacting with this assay in faeces during mucositis is not likely to have influenced the performance of the PA ELISA assay when serum samples are tested.

Acknowledgements Part of the study has been presented during the 49th Interscience Conference on Antimicrobial Agents and Chemotherapy, San Francisco, California, September 12-15, 2009.

The Ministry of Health (IGA NS10442-3/2009 and IGA NS10441-3/2009) of the Czech Republic and the Ministry of Education, Youth and Sports (MSMT6198959223 and MSMT0021622430) of the Czech Republic supported this work.

Potential conflicts of interest All authors: no conflict. 


\section{References}

1. Pfeiffer CD, Fine JP, Safdar N (2006) Diagnosis of invasive aspergillosis using a galactomannan assay: a meta-analysis. Clin Infect Dis 42(10):1417-1427

2. Walsh TJ, Shoham S, Petraitiene R, Sein T, Schaufele R, Kelaher A, Murray H, Mya-San C, Bacher J, Petraitis V (2004) Detection of galactomannan antigenemia in patients receiving piperacillintazobactam and correlations between in vitro, in vivo, and clinical properties of the drug-antigen interaction. J Clin Microbiol 42 (10):4744-4748

3. Racil Z, Kocmanova I, Lengerova M, Winterova J, Mayer J (2007) Intravenous PLASMA-LYTE as a major cause of false-positive results of platelia Aspergillus test for galactomannan detection in serum. J Clin Microbiol 45(9):3141-3142

4. Ansorg R, van den Boom R, Rath PM (1997) Detection of Aspergillus galactomannan antigen in foods and antibiotics. Mycoses 40(9-10):353-357

5. Herbrecht R, Letscher-Bru V, Oprea C, Lioure B, Waller J, Campos F, Villard O, Liu KL, Natarajan-Amé S, Lutz P, Dufour P, Bergerat JP, Candolfi E (2002) Aspergillus galactomannan detection in the diagnosis of invasive aspergillosis in cancer patients. J Clin Oncol 20(7):1898-1906

6. World Health Organization (WHO) (1979) WHO handbook for reporting results of cancer treatment. WHO, Geneva, pp 15-22
7. National Cancer Institute (2006) Common Terminology Criteria for Adverse Events (CTCAE) v3.0. 2006. Available online at: http:// ctep.cancer.gov/reporting/ctc.html. Accessed 9 November 2009

8. Ascioglu S, Rex JH, de Pauw B, Bennett JE, Bille J, Crokaert F, Denning DW, Donnelly JP, Edwards JE, Erjavec Z, Fiere D, Lortholary O, Maertens J, Meis JF, Patterson TF, Ritter J, Selleslag D, Shah PM, Stevens DA, Walsh TJ (2002) Defining opportunistic invasive fungal infections in immunocompromised patients with cancer and hematopoietic stem cell transplants: an international consensus. Clin Infect Dis 34(1):7-14

9. Mennink-Kersten MA, Donnelly JP, Verweij PE (2004) Detection of circulating galactomannan for the diagnosis and management of invasive aspergillosis. Lancet Infect Dis 4(6):349-357

10. Mennink-Kersten MA, Ruegebrink D, Klont RR, Warris A, Gavini F, Op den Camp HJ, Verweij PE (2005) Bifidobacterial lipoglycan as a new cause for false-positive platelia Aspergillus enzyme-linked immunosorbent assay reactivity. J Clin Microbiol 43(8):3925-3931

11. Maertens J, Van Eldere J, Verhaegen J, Verbeken E, Verschakelen J, Boogaerts M (2002) Use of circulating galactomannan screening for early diagnosis of invasive aspergillosis in allogeneic stem cell transplant recipients. J Infect Dis 186(9):1297-1306

12. Blijlevens NM, Donnelly JP, Meis JF, Verweij PE, de Pauw BE (2002) Aspergillus galactomannan antigen levels in allogeneic haematopoietic stem cell transplant recipients given total parenteral nutrition. Transpl Infect Dis 4(2):64-65 